\title{
A Micellar Mitotane Formulation with High Drug-Loading and Solubility: Physico-Chemical Characterization and Cytotoxicity Studies in 2D and 3D In Vitro Tumor Models
}

\author{
Malik Salman Haider, Jochen Schreiner, Sabine Kendl, Matthias Kroiss, * \\ and Robert Luxenhofer:
}

\begin{abstract}
Adrenocortical carcinoma (ACC) is a rare tumor and prognosis is overall poor but heterogeneous. Mitotane (MT) has been used for treatment of ACC for decades, either alone or in combination with cytotoxic chemotherapy. Even at doses up to $6 \mathrm{~g}$ per day, more than half of the patients do not achieve targeted plasma concentration (14-20 $\mathrm{mg} \mathrm{L}^{-1}$ ) even after many months of treatment due to low water solubility, bioavailability, and unfavorable pharmacokinetic profile. Here a novel MT nanoformulation with very high MT concentrations in physiological aqueous media is reported. The MT-loaded nanoformulations are characterized by Fourier transform infrared spectroscopy, differential scanning calorimetry, and powder X-ray diffraction which confirms the amorphous nature of the drug. The polymer itself does not show any cytotoxicity in adrenal and liver cell lines. By using the ACC model cell line NCI-H295 both in monolayers and tumor cell spheroids, micellar MT is demonstrated to exhibit comparable efficacy to its ethanol solution. It is postulated that this formulation will be suitable for i.v. application and rapid attainment of therapeutic plasma concentrations. In conclusion, the micellar formulation is considered a promising tool to alleviate major drawbacks of current MT treatment while retaining bioactivity toward ACC in vitro.
\end{abstract}

\section{Introduction}

Adrenocortical carcinoma (ACC) is a highly aggressive malignant disease with a high risk of recurrence even after complete resection and heterogeneous but generally poor prognosis in advanced stages. ${ }^{[1-3]}$ In the majority of the cases, patients with ACC present with hormonal excess, mostly Cushing's syndrome and symptoms of sex steroid excess. Patients without hormone overproduction generally are diagnosed due to symptoms of local tumor growth or symptomatic metastases. The therapeutic challenge is to both control hormone excess and to combat tumor progression. ${ }^{[4]}$

The only approved treatment for ACC is the adrenolytic drug 1,1-dichloro-2-(ochlorophenyl)-2-(p-chlorophenyl)ethane, better known by its trivial name mitotane (MT). MT is used both as adjuvant therapy after complete tumor resection and as palliative treatment in case of advance disease. Only recently, the presumed key molecular mechanism of action was shown to be inhibition of sterol-O-acyl transferase $1^{[5]}$ but additional drug effects, for example, at the level of mitochondria have been reported.[6,7] Based on the results obtained from a large randomized phase III clinical trial, the combination of oral MT with intravenous administration of etoposide, doxorubicin, and cisplatin is currently considered as treatment standard for advanced ACC. ${ }^{[8,9]}$ Mitotane $500 \mathrm{mg}$ tablets are marketed in Europe as Lysodren by HRA Pharma, Paris and in the U.S. by Bristol-Myers Squibb. Treatment with MT is hampered by its severe side effects to the central nervous system (dizziness, speech difficulties, stroke-like symptoms), liver, and gastrointestinal tract. ${ }^{[10-12]}$ While serum concentrations above $14 \mathrm{mg} \mathrm{L}^{-1}$ have been reported to be associated with the therapeutic response, ${ }^{[13-16]}$ the incidence of toxic effects increases beyond $20 \mathrm{mg} \mathrm{L}^{-1}$ leading to a narrow therapeutic window and the requirement of therapeutic drug monitoring. Management is further complicated by unfavorable pharmacokinetic properties of MT. Even at high cumulative doses of 4 to $6 \mathrm{~g}$ per day for a consecutive of 3 months, more than half of the patients do not achieve targeted plasma concentration. ${ }^{[3,17]}$ Overall, MT pharmacokinetics exhibit large inter-individual variability which appears to be due in part due intestinal ${ }^{[18]}$ and/or hepatic

DOI: 10.1002/mabi.201900178 
metabolism. ${ }^{[19]}$ The inactive metabolite $o, p^{\prime}$-DDA is also found ten times higher in blood than the active parent compound MT. ${ }^{[20-22]}$ The evidence that MT is strong inducer of hepatic cytochromeP450 enzyme further strengthens its hepatic metabolism. ${ }^{[23-26]}$

MT's limited aqueous solubility of $0.1 \mathrm{mg} \mathrm{L}^{-1[27]}$ is likely the cause of poor and variable oral absorption ${ }^{[28]}$ and high volume of distribution. ${ }^{[29]}$ Efforts in the past have been undertaken to shorten the time interval to reach the therapeutic serum/plasma concentrations and reduce the gastrointestinal side effects. Attivi et al. reported a self-micro-emulsifying drug delivery system (SMEDDS). MT was dissolved in various oils and surfactants (in ratio of 1:16) as individual or in the various binary and ternary mixtures (33\% caproyl, 33\% tween, and 33\% cremophore EL). The solubility of MT in individual vehicle was maximal with $409 \mathrm{~g} \mathrm{~L}^{-1}$ in cremophore EL. The relative bioavailability in rabbits at a dose of $100 \mathrm{mg} \mathrm{kg}^{-1}$ body weight was increased by a factor of 3.4 for the MT emulsion. ${ }^{[30]}$ Battung and coworkers filed a patent about the development of an oily formulation (SMEDDS) of MT (based on propylene glycol monocaprylate, propylene glycol dicaprate and polyoxyethylene sorbitan monooleate). They were capable of solubilizing $0.4 \mathrm{~g}$ of MT per gram of oily vehicle (28 wt\%). In vivo studies were conducted in Beagle dogs and the relative bioavailability was increased by factor of 3.2 for the oily formulation. ${ }^{[31,32]}$

Lipophilicity of MT has been shown to result in predominant association with serum lipoproteins (LPs) ${ }^{[33,34]}$ and also chyle ${ }^{[18]}$ but only free MT was demonstrated to be therapeutically active. ${ }^{[35,36]}$ Collectively, poor aqueous solubility and difficult to predict PK profile of MT are the major obstacles in MT therapy. Here, we aimed at the development of a novel MT nanoformulations, which may enable both an injectable formulation and could increase bioavailability when administered orally and hence shorten the long lag time, which is arguably the biggest problem of MT in the clinics.

Micelles are formed by the self-assembly of amphiphilic molecules. Several polymeric micelles formulations have been widely studied in preclinical and clinical trials which have shown improved pharmacological activity and less systemic toxicity. ${ }^{[37-42]}$ Poly(2-oxazoline)s (POx) have been discussed as potential biomaterial for decades but the major advancements have been seen in the last few years. ${ }^{[43,44]}$ In particular, poly(2methyl-2-oxazoline)-block-poly(2-butyl-2-oxazoline)-blockpoly(2-methyl-2-oxazoline) (pMeOx-pBuOx-pMeOx) being the most investigated amphiphile of this polymer family has shown a huge potential for not only solubilizing hydrophobic drugs but also exhibited high cytocompatibility. ${ }^{[45,46]}$ Accordingly, we set out to develop a novel pMeOx-pBuOx-pMeOx based MT nanoformulation with high drug loading. The formulation was comprehensively characterized and the bioactivity of the solubilized MT was assessed in 2D and 3D cell culture using NCIH295 adrenocortical carcinoma cell line. Our results suggest that this novel MT nanoformulation is suitable for i.v. administration and thus may alleviate the biggest clinical problem of MT, its poor bioavailability and unfavorable pharmacokinetics.

\section{Experimental Section}

All substances for the preparation of polymer and bovine serum albumin (BSA) were purchased from Sigma-Aldrich (Steinheim,
Germany) or Acros (Geel, Belgium) and were used as purchased unless stated otherwise. Mitotane was purchased from ISP chemical products, Columbus, USA. The monomer 2-n-butyl2-oxazoline $(\mathrm{BuOx})$ was prepared according to the original procedure by Seeliger et al. ${ }^{[47]}$ as modified and reported recently. ${ }^{[48]}$ All substances used for polymerization, methyl trifluoromethylsulfonate (MeOTf), 2-methyl-2-oxazoline and other solvents for polymer preparation were refluxed over $\mathrm{CaH}_{2}$, while benzonitrile $(\mathrm{PhCN})$ was refluxed over $\mathrm{P}_{2} \mathrm{O}_{5}$ and distilled under argon. Deuterated solvents for NMR analysis were purchased from Deutero GmbH (Kastellaun, Germany). Phosphate-buffered saline (PBS) was prepared by dissolving $8.0 \mathrm{~g}(137 \mathrm{mmol}) \mathrm{NaCl}$, $0.2 \mathrm{~g}(2.7 \mathrm{mmol}) \mathrm{KCl}, 1.42 \mathrm{~g}(10 \mathrm{mmol}) \mathrm{Na}_{2} \mathrm{HPO}_{4}$, and $0.27 \mathrm{~g}$ $(1.98 \mathrm{mmol}) \mathrm{KH}_{2} \mathrm{PO}_{4}$ in $1.0 \mathrm{~L}$ of deionized (DI) water (pH 7.4 at $25^{\circ} \mathrm{C}$ ). If necessary, $\mathrm{pH}$ was adjusted to 7.4 with aqueous $\mathrm{HCl}$ or $\mathrm{NaOH}$ solution.

\subsection{Polymer Synthesis}

The polymerizations and work-up procedures were carried out as described previously. ${ }^{[48-50]}$ As an example, the synthesis of A-pBuOx-A was performed as follows.

The initiator, MeOTf was added to a dried and argon flushed flask and dissolved in PhCN. MeOx was added and the reaction mixture was heated to $110^{\circ} \mathrm{C}$ for approximately $4 \mathrm{~h}$. Reaction progress was controlled by Fourier-transform infrared (FTIR) and ${ }^{1} \mathrm{H}$-NMR-spectroscopy. After complete consumption of $\mathrm{MeOx}$, the mixture was cooled to RT and the monomer for the second block $(\mathrm{BuOx})$ was added. The reaction mixture was heated to $120^{\circ} \mathrm{C}$ and kept on stirring overnight. The procedure was repeated for the third block (MeOx) and after full monomer consumption was confirmed, termination was carried out by addition of 5 eq. of $1 \mathrm{~m} \mathrm{NaOH}$ solution in DI water (Polymer batch: P1) or 3 equivalents of piperidine (Polymer batch: P2) at $50{ }^{\circ} \mathrm{C}$ for $4 \mathrm{~h}$. Subsequently, 1 eq. of $\mathrm{K}_{2} \mathrm{CO}_{3}$ (only in P2) was added and the mixture was stirred at $50{ }^{\circ} \mathrm{C}$ for $4 \mathrm{~h}$. PhCN was removed under reduced pressure. The highly viscous residues were dissolved in DI water and transferred into a dialysis bag (MWCO $1 \mathrm{kDa}$, cellulose acetate) and dialyzed against DI water for $24 \mathrm{~h}$. The solution was recovered from the bag and lyophilized. The products were obtained as colorless powders.

\subsection{Nuclear Magnetic Resonance Spectroscopy}

NMR spectra were recorded on a Fourier 300 (300.12 MHz), Bruker Biospin (Rheinstetten, Germany) at $298 \mathrm{~K}$. The spectra were calibrated to the signal of residual protonated solvent $\left(\mathrm{CDCl}_{3}\right.$ at $\left.7.26 \mathrm{ppm}\right)$ using MestReNova software.

\subsection{Dialysis}

Dialysis was performed using Spectra/Por membranes with a molecular weight cutoff (MWCO) of $1 \mathrm{kDa}$ (material: cellulose acetate) obtained from neoLab (Heidelberg, Germany). DI water was renewed after 1,4 , and every $12 \mathrm{~h}$ subsequently, until the end of dialysis. 


\subsection{Gel Permeation Chromatography}

Gel permeation chromatography (GPC) was performed on an Agilent 1260 Infinity System, Polymer Standard Service (Mainz, Germany) with HFIP containing $3 \mathrm{~g} \mathrm{~L}^{-1}$ potassium trifluoroacetate; precolumn: $50 \mathrm{~mm} \times 8 \mathrm{~mm}$ PSS PFG linear M; 2 columns: $300 \mathrm{~mm} \times 8 \mathrm{~mm}$ PSS PFG linear M (particle size $7 \mu \mathrm{m}$; pore size $0.1-1000 \mathrm{kDa}$ ). The columns were kept at $40{ }^{\circ} \mathrm{C}$ and

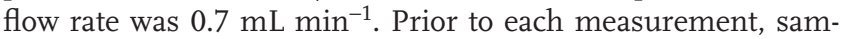
ples were filtered through $0.2 \mu \mathrm{m}$ PTFE filters, Roth (Karlsruhe, Germany). Conventional calibration was performed with PEG standards $\left(0.1-1000 \mathrm{~kg} \mathrm{~mol}^{-1}\right)$ and data was processed with Win-GPC software.

\subsection{Drug Formulation}

Drug loaded polymer micelles were prepared using the thin film method. Ethanolic polymer $\left(10 \mathrm{~g} \mathrm{~L}^{-1}\right)$ and MT $\left(10 \mathrm{~g} \mathrm{~L}^{-1}\right)$ stock solutions were mixed in desired ratios. After complete removal of the solvent at $50{ }^{\circ} \mathrm{C}$ under a mild stream of argon, the films were dried in vacuo $(\leq 0.2 \mathrm{mbar})$ for at least $30 \mathrm{~min}$. Subsequently, preheated $\left(37^{\circ} \mathrm{C}\right)$ DI water, PBS, or aqueous serum albumin solution $\left(40 \mathrm{~g} \mathrm{~L}^{-1}\right)$ was added to obtain desired final polymer $\left(10 \mathrm{~g} \mathrm{~L}^{-1}\right)$ and MT concentrations. To ensure complete solubilisation, the solutions were shaken at $55{ }^{\circ} \mathrm{C}$ for $15 \mathrm{~min}$ at $1250 \mathrm{rpm}$ with a Thermomixer comfort (Eppendorf AG, Hamburg, Germany). Non-solubilized drug was removed by centrifugation for $5 \mathrm{~min}$ at $10.000 \mathrm{rpm}$ with a 3-Speed micro centrifuge, (neoLab, Heidelberg, Germany). Solubilisation experiments were performed with three individually prepared samples and results are presented as means \pm standard deviation (SD).

\subsection{High Performance Liquid Chromatography}

HPLC analysis was carried out on a LC-20A Prominence HPLC (Shimadzu, Duisburg, Germany) equipped with a system controller CBM-20A, a solvent delivery unit LC-20 AT (double plunger), an on-line degassing unit DGU-20A, an auto-sampler SIL-20AC, a photo diode array detector SPD-M20A. As stationary phase, a ZORBAX Eclipse Plus (Agilent, Santa Clara, CA, USA) C18 column (4.6 mm $\times 100 \mathrm{~mm}$; $3.5 \mu \mathrm{m}$ ) was used. Quantification of MT was performed with a stepwise gradient. Within the first $10 \mathrm{~min}$, the ratio of $\mathrm{H}_{2} \mathrm{O} / \mathrm{ACN}$ was decreased from $60 / 40(\mathrm{v} / \mathrm{v})$ to $40 / 60(\mathrm{v} / \mathrm{v})$. Solvent ratio was kept constant for $5 \mathrm{~min}$, prior to increasing it to the initial ratio of $60 / 40(\mathrm{v} / \mathrm{v})$ within $0.5 \mathrm{~min}$. This ratio was kept for $5 \mathrm{~min}$. Flow rate was

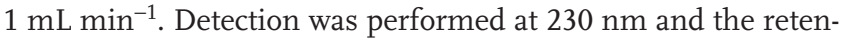
tion time was $3.9 \mathrm{~min}$.

\subsection{Loading Capacity and Loading Efficiency}

The following equations were used to calculate the loading capacity (LC) and loading efficiency (LE) of the formulations:

$\mathrm{LC}=\frac{m_{\text {drug }}}{m_{\text {drug }}+m_{\text {excipient }}} * 100 \%$
$\mathrm{LE}=\frac{m_{\text {drug }}}{m_{\text {drug,added }}} * 100 \%$

where $m_{\text {drug }}$ and $m_{\text {excipient }}$ are the weight amounts of the solubilized drug and polymer excipient in solution and $m_{\text {drug,added }}$ is the weight amount of the drug initially added to the dispersion. No loss of polymer during micelles preparation was assumed.

\subsection{Long Term Stability Studies}

For long term stability studies, formulated MT was stored at ambient conditions $\left(\approx 25{ }^{\circ} \mathrm{C}\right)$ under the exclusion of light. The samples were collected at day $0,1,2,3,4,5,10,20$, and day 30 . Before the determination of the drug loading by HPLC, all samples were centrifuged for $5 \mathrm{~min}$ at $10000 \mathrm{rpm}$ with a 3-Speed micro centrifuge (neoLab, Heidelberg, Germany). Long-term stabilization experiments were performed with three individually prepared samples and results are presented as means $\pm \mathrm{SD}$, quantification was carried out as described above.

\subsection{Redispersion Studies}

The freshly prepared formulations were frozen in liquid nitrogen and subjected to $24 \mathrm{~h}$ lyophilization to obtain the dried powdered MT formulation for redispersion studies. The media used for the redispersion (keeping the polymer concentration $10 \mathrm{~g} \mathrm{~L}^{-1}$ ) were DI water, cell culture medium, PBS, and PBS with $40 \mathrm{~g} \mathrm{~L}^{-1}$ BSA. The formulations were shaken at $1250 \mathrm{rpm}$ with a Thermomixer comfort (Eppendorf $A G$, Hamburg, Germany) at room temperature for $10 \mathrm{~min}$ followed by HPLC analysis as stated in section long-term stability studies.

\subsection{Polymer Drug Compatibility Evaluation by Hansen Solubility Parameters}

The extent of compatibility between MT and the core forming block of the ABA triblock copolymers was calculated by employing the Hildebrand-Scatchard equation: ${ }^{[51]}$

$\chi_{\text {drug-polymer }}=\left(\delta_{\text {drug }}-\delta_{\text {polymer }}\right)^{2} \frac{V}{R T}$

where $\chi_{\text {drug-polymer }}\left(\chi_{d p}\right)$ is Flory-Huggins interaction parameter, $\delta_{\text {drug }}$ and $\delta_{\text {polymer }}$ are the total solubility parameter $\left(\delta_{\text {total }}\right)$ for the MT and the core forming block, respectively. $V$ is the molar volume of MT calculated by Fedors methods, ${ }^{[52]}$ while $R$ is the gas constant and $T$ is the temperature. The $\delta_{\text {total }}$ (also called as $3 \mathrm{D}$ solubility parameter) that is, $\delta_{\text {drug }}$ and $\delta_{\text {polymer }}$ were further calculated by following equations:

$\delta_{\text {drug }}^{2}=\delta_{d}^{2}+\delta_{p}^{2}+\delta_{h}^{2}$
$\delta_{\text {polymer }}^{2}=\delta_{d}^{2}=\delta_{p}^{2}+\delta_{h}^{2}$ 
The $\delta_{\text {total }}$ is the sum of dispersion $\left(\delta_{d}\right)$, polar $\left(\delta_{p}\right)$ and hydrogen bonding forces $\left(\delta_{h}\right)$. The $\delta_{d}, \delta_{p}$, and $\delta_{h}$ were further calculated by Hoftyzer and Van Krevelen's additive group contribution method by employing the following equations:

$\delta_{d}=\frac{\sum F_{d i}}{V}$

$\delta_{p}=\frac{\left(\Sigma F_{p i}^{2}\right)^{1 / 2}}{V}$

$\delta_{h}=\left(\Sigma \frac{E_{h i}}{V}\right)^{1 / 2}$

where $F_{d i}, F_{p i}$, and $E_{h i}$ are the molar dispersion, polar attraction constant and hydrogen bonding energy, respectively. Each structural group in the molecule contributes towards the $F_{d i}$, $F_{p i}$, and $E_{h i}$.

\subsection{Fourier Transform Infrared Spectroscopy}

The FT-IR spectra were recorded on a FT-IR-4100 (Jasco, GrossUmstadt, Germany), measuring from 500 to $4000 \mathrm{~cm}^{-1}$. The aqueous MT formulations were lyophilized to obtain the dry powdered formulation prior to FT-IR measurements.

\subsection{Differential Scanning Calorimetry}

For DSC studies samples were placed into flat-bottom aluminum pans with the pierced lids. The aqueous MT formulations were lyophilized to obtain the dry powdered formulation prior to DSC measurements.

DSC was performed on DSC 204 F1 Phoenix equipped with a CC200 F1 Controller, (NETZSCH, Selb, Germany). The dynamic scans were recorded in nitrogen atmosphere with a heating rate of $10 \mathrm{~K} \mathrm{~min}^{-1}\left(25-200{ }^{\circ} \mathrm{C}\right)$ and subsequently cooled to $-50{ }^{\circ} \mathrm{C}\left(10 \mathrm{~K} \mathrm{~min}^{-1}\right)$. The samples were heated and cooled two additional times from -50 to $200{ }^{\circ} \mathrm{C}\left(10 \mathrm{~K} \mathrm{~min}^{-1}\right)$ (three heating and two cooling cycles).

\subsection{X-Ray Diffraction}

Powder X-ray diffraction (XRD) was performed at STADI P from STOE (STOE \& Cie GmbH, Darmstadt Germany). The setup is equipped with radiation source of $\mathrm{Cu}-\mathrm{K} \alpha$ and the detector is linear PSD. Measurement were done at $0.15^{\circ}$ steps each step lasting $180 \mathrm{~s}$ in transmission mode at $40 \mathrm{kV}$ voltage and $30 \mathrm{~mA}$ current and $2 \Theta$ angle ranging from $5^{\circ}$ to $60^{\circ}$ were used.

\subsection{Dynamic Light Scattering}

Dynamic light scattering were measured on Zetasizer Nano ZSP from Malvern, (Malvern Instruments, Worcestershire,
UK) in disposable cuvettes (UV cuvettes semi micro, BRAND $\mathrm{GmbH}$, Wertheim, Germany) at ambient temperatures $\left(\approx 25^{\circ} \mathrm{C}\right)$. Data was analyzed by using zetasizer software 7.11. All the samples were measured after filtration using $0.45 \mu \mathrm{m}$ PVDF syringe filter (Rotilabo, Karlsruhe). The filtered samples were further diluted (1:1 ratio with DI water) and measured again to exclude variation due to dilution effect (Figure S11, Supporting Information). The measurements were recorded as average of three test runs for two individually prepared samples.

\subsection{Cell Culture}

The adherent adrenocortical cell line NCI-H295R (ATCC, USA) ${ }^{[53]}$ and HepG2 cell line (ATCC, USA) were grown in DEMEM/F-12 1:1 mix (Gibco, USA) supplemented with 1\% insulin-transferrin-selenium (Gibco, USA) and 3\% Nu-Serum (Corning, USA). Cells were cultured at $37{ }^{\circ} \mathrm{C}$ and $5 \% \mathrm{CO}_{2}$ humid atmosphere in flasks.

\subsection{Monolayer Culture and Spheroid Formation}

For monolayer cell culture, $1 \times 10^{5}$ cells were seeded in a flat bottom 96-well plate in 100 and $200 \mu \mathrm{L}$ medium for cytocompatibility studies and cytotoxicity studies, respectively, and incubated for $24 \mathrm{~h}$. For spheroid formation $5 \times 10^{4}$ cells were seeded in 96-well plates, coated with $50 \mu \mathrm{L} 1.5 \%$ autoclaved agarose (Sigma-Aldrich, Germany) in a total volume of $200 \mu \mathrm{L}$ culture medium. Initially, the spheroid formation was induced by centrifugation at $1 \mathrm{~g}$ for $3 \mathrm{~min}$. Medium was refreshed after $48 \mathrm{~h}$ by exchanging $100 \mu \mathrm{L}$ of supernatant. After $96 \mathrm{~h}$ spheroids were formed in each well.

\subsection{Cytocompatibility Studies}

The cytocompatibility studies of the polymer alone (both polymer batches, P1 and P2) were performed on monolayer culture of HepG2 cell line and NCI-H295R. The cells were cultured as stated, after $24 \mathrm{~h}$ incubation the monolayers were exposed to various polymer concentrations, that is, $1,5,10$, 25,50 , and $100 \mathrm{~g} \mathrm{~L}^{-1}$ (prepared in cell culture medium). Treated plates were incubated for 6 and $24 \mathrm{~h}$. Cell viability was assessed by WST1 (NCI-H295R and HepG2 cells) and cellTiter-Glo-3D-assay (Promega, Germany) (NCI-H295R). Briefly, after the incubation time of 6 and $24 \mathrm{~h}$ the treated plates (with HepG2 cells) were exposed to WST1 reagent (10 $\mu \mathrm{L}$ in each well). The plates were further incubated for $2 \mathrm{~h}$ followed by the absorbance measurement by multilabel plate reader Wallac Victor 1420 (PerkinElmer, USA). CellTiterGlo-3D assay was performed according to the manufacturer's instructions. $150 \mu \mathrm{L}$ of supernatant was removed and replaced with $50 \mu \mathrm{L}$ of CellTiter-Glo-3D-Reagent. Cell lysis was induced by mixing with multichannel pipettes and the lysate was transferred to opaque plates. After $25 \mathrm{~min}$ of incubation luminescence was measured by multilabel plate reader Wallac Victor 1420 (PerkinElmer, USA). 


\subsection{Cytotoxicity Studies in 2D and 3D Cell Spheroids}

The efficacy of MT formulated in micelles or MT dissolved in EtOH was comparatively assed in 2D cell culture and 3D cell spheroids. Mitotane treatment was performed after $24 \mathrm{~h}$ of culturing for monolayer and $96 \mathrm{~h}$ for spheroids culture in a 96 well-plate, by removing $100 \mu \mathrm{L}$ medium and adding $100 \mu \mathrm{L}$ culture medium containing either mitotane-EtOH or mitotane in micelles to attain final concentrations ranging from 5 to $75 \mu \mathrm{M}$ and 50 to $200 \mu \mathrm{M}$ for monolayer and spheroids, respectively. Various stock solutions of mitotane in micelles $(2 \mathrm{~mm}$ stock solution, prepared in cell culture medium) and mitotane-EtOH (MT was dissolved in absolute ethanol in 500-20 mm stock solutions) were prepared. Stocks solutions were further diluted with cell culture medium to obtain final concentrations. EtOH concentration was $1 \%(\mathrm{v} / \mathrm{v})$ in all mitotane-EtOH samples and controls. Treated plates were incubated for 24 and $48 \mathrm{~h}$. All experiments were performed in triplicate with $n=8$ in each replicate, unless specified otherwise.

\subsection{Statistical Analysis}

Statistical analysis was performed using two-way ANOVA using GraphPad prism software version 5.01. Statistical significance was calculated by applying Bonferroni post hoc tests.

\section{Results and Discussions}

\subsection{Polymer Synthesis and Characterization}

Block copolymers of POx are easily accessible by living cationic ring-opening polymerization (LCROP) and POx amphiphiles are highly tunable with respect to solubility, size, architecture as well chemical functionality. ${ }^{[54-57]}$ All polymers in this study were also synthesized by LCROP using methyltriflate as an initiator (MeOTf) as previously described. ${ }^{[4,50]}$ All ABA triblock copolymers comprised hydrophilic pMeOx as block A and poly(2-n-propyl-2-oxazoline) (pPrOx), poly(2-n-propyl-2-oxazine) (pPrOzi), poly(2-n-butyl-2-oxazoline) (pBuOx), poly(2-benzyl2-oxazoline) (pBzOx), and poly(2-n-butyl-2-oxazine) (pBuOzi) as hydrophobic block B, respectively (Table 1). Two polymer batches of pBuOx based triblock copolymer (P1 and P2) were

Table 1. Physicochemical characterization of all the polymers used in this study including the molecular weight $M_{n}$ and dispersity $Ð$.

\begin{tabular}{lccl}
\hline Polymer & $M_{\mathrm{n}}^{\mathrm{a})}\left[\mathrm{kg} \mathrm{mol}^{-1}\right]$ & $M_{\mathrm{n}}^{\mathrm{b})}\left[\mathrm{kg} \mathrm{mol}^{-1}\right]$ HFIP & $\Xi^{\mathrm{b})}$ \\
\hline $\mathrm{A}_{41}-\mathrm{pPrOx}_{23}-\mathrm{A}_{40}$ & 9.7 & 4.7 & 1.19 \\
$\mathrm{~A}_{35}-\mathrm{pPrOzi}_{20}-\mathrm{A}_{35}$ & 8.7 & 5.4 & 1.19 \\
$\mathrm{~A}_{33}-\mathrm{pBuOx}_{20}-\mathrm{A}_{33}(\mathrm{P1})$ & 8.1 & 3.6 & 1.10 \\
$\mathrm{~A}_{32}-\mathrm{pBuOx}_{20}-\mathrm{A}_{32}(\mathrm{P} 2)$ & 8.0 & 5.6 & 1.10 \\
$\mathrm{~A}_{40}-\mathrm{pBzOx}_{20}-\mathrm{A}_{41}$ & 10.3 & 5.2 & 1.25 \\
$\mathrm{~A}_{35}-\mathrm{pBuOzi}_{20}-\mathrm{A}_{35}$ & 9.0 & 5.6 & 1.20 \\
\hline
\end{tabular}

a) obtained by ${ }^{1} \mathrm{H}-\mathrm{NMR}$ analysis $\left(\mathrm{CDCl}_{3} ; 300 \mathrm{MHz}\right)$; b) obtained by $\mathrm{GPC}$ analysis (eluent: HFIP, PEG calibration). The values are taken from the refs. $[48,50]$. synthesized specifically for this contribution and terminated with $\mathrm{NaOH} /$ water and piperidine, respectively. In our previous work, we have observed relatively minor effect of the polymer termini in poly(2-oxazoline)/poly(2-oxazine) (POx/POzi) based ABA triblock copolymers, but this may have to be assessed on a case-by-case basis. ${ }^{[46,58]}$ Both batches were characterized by ${ }^{1} \mathrm{H}$ NMR and GPC. A satisfactory synthetic control was achieved in both batches of the polymer, supporting the excellent reproducibility for this polymer synthesis. ${ }^{[5]}$ For further analytical details, please see Table 1 and supporting information (Figures S1-S7, Supporting Information).

\subsection{Formulation Studies}

\subsubsection{Formulation Development}

POx-based amphiphiles have tremendous potential for formulation development. ${ }^{[45,58,60,61]}$ For example, Milonaki et al. reported very high drug loading with indomethacin using an (pseudo-diblock) copolymers from 2-methyl-2-oxazoline and 2-phenyl-2-oxazoline. ${ }^{[61]}$ Luxenhofer et al. ${ }^{[58]}$ reported the ultrahigh paclitaxel (PTX)-loaded POx-based micellar formulation with very promising in vivo data. The lead amphiphile is a ABA triblock copolymer, A and B being comprised of hydrophilic poly(2-methyl-2-oxazoline) (pMeOx) and modestly hydrophobic poly(2-butyl-2-oxazoline) (pBuOx), respectively (pMeOx-pBuOxpMeOx). The loading capacity (LC) was found to be $50 \mathrm{wt} \%$ corresponding to an increase of solubility of PTX over five order of magnitude to $50 \mathrm{~g} \mathrm{~L}^{-1}$. PTX/POx formulation showed superior antitumor efficacy with the maximum tolerated dose (MTD) of $150 \mathrm{mg} \mathrm{kg}^{-1}$ when compared to commercially available formulations, that is, Taxol and Abraxane (MTD being 20 and $90 \mathrm{mg}$ $\mathrm{kg}^{-1}$, respectively). ${ }^{[60]}$ Wan et al. recently reported the co-formulation of etoposide (ETO) and a hydrophobized cisplatin (Cis) using the similar amphiphile (pMeOx-pBuOx-pMeOx). This co-formulation demonstrated superior antitumor efficacy on various small cell and non-small cell lung cancer models as compared to single drug micelles or their combination as well as free drug combination. ${ }^{[62]}$

It is an usual assumption that the hydrophobic block is mainly responsible for solubilisation of hydrophobic drugs and that increasing the hydrophobicity of the core forming block (B) can increase the solubilisation capacity of an amphiphile. More recently, more specific interactions between polymers and their cargo have come into the focus of researchers. ${ }^{[63,64]}$ In the case of POx-based amphiphiles an inverse relationship between the hydrophobicity of the micellar core and the drugloading capacity has been observed repeatedly. Lübtow et al.[49] have recently reported a study on this behavior showing that POx- and POzi-based ABA triblock copolymer with long linear or branched side chains, that is (poly(2-nonyl-2-oxazoline) (pNonOx) or (poly(2-(3-ethylheptyl)-2-oxazoline) (pEtHepOx) rather negatively affect the LCs for hydrophobic drugs, curcumin (CUR) and PTX. Besides higher solubilizing capacity of short side chain core forming blocks, Lübtow et al. ${ }^{[48]}$ further reported that minor changes in the chemical structure of short side chain core forming blocks, that is, a formal transition of one methylene unit from side chain ( $\mathrm{pBuOx}$ ) to the back bone 

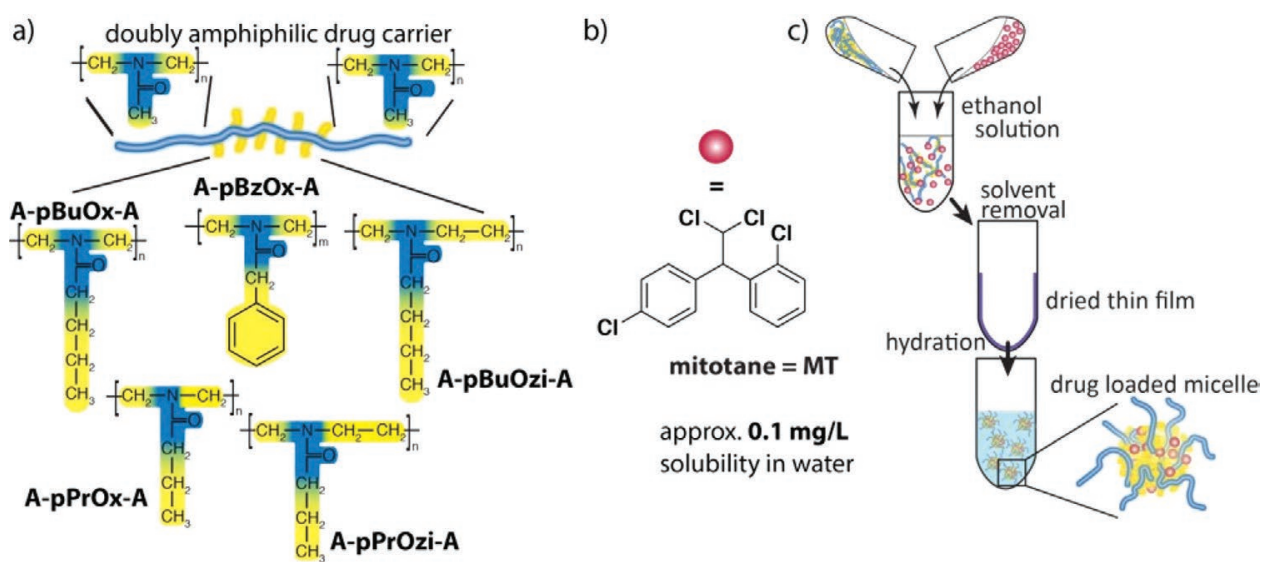

Figure 1. a) Schematic representation of the polymers used in this this study. b) Chemical structure of Mitotane and c) schematic illustration of thin film hydration method for formulation development.

(pPrOzi) or introduction of aromatic moieties ${ }^{[50]}$ have significant impact on the LCs for hydrophobic drugs, indicating very strong polymer/drug specificities.

Accordingly, the solubilization of MT, which exhibits an extremely low water solubility, ${ }^{[27]}$ zero H-bond donor groups, and higher aromatic character, was tested using five different ABA triblock copolymers including the most commonly investigated ABA triblock amphiphile, that is, A-pBuOx-A, and A-pPrOzi-A, A-pBuOzi-A, A-pPrOx-A, and A-pBzOx-A (Figure 1c and Table 1). The polymers with short linear side chain (which have been shown to optimally solubilize various hydrophobic drugs) ${ }^{[48,58]}$ or with the aromatic content (inspired by a potential benefit of $\pi$ - $\pi$ stacking between drug and carrier $)^{[50,65,66]}$ were specifically selected to find a good MT solubilizer, for which only very few formulations are reported to date. ${ }^{[30,67]}$ Using the thin-film approach (Figure 1b), we prepared micellar formulations of MT with the aforementioned amphiphilic triblock copolymers (Table S1, Supporting Information). Briefly, the polymer and MT were dissolved in ethanol, which was subsequently removed and the resulting thin-film was dissolved by adding DI water. We kept the targeted polymer concentration at $10 \mathrm{~g} \mathrm{~L}^{-1}$ and increased the targeted MT concentration from 2 to $10 \mathrm{~g} \mathrm{~L}^{-1}$. The actual MT concentration achieved in the aqueous phase was assessed using HPLC (Figure 2a) after removal of non-solubilized drug.

Increasing the MT feed from 2 to $10 \mathrm{~g} \mathrm{~L}^{-1}$ raised the LC from 11 to $36 \mathrm{wt} \%$ (1.25 and $5.7 \mathrm{~g} \mathrm{~L}^{-1}$, respectively) (Table S1S3, Supporting Information). A-pBuOx-A being the best solubilizer for PTX, ${ }^{[58]}$ also gives the highest MT loading among the tested amphiphiles. Up to $6 \mathrm{~g} \mathrm{~L}^{-1}$ (19 mm) MT could be obtained as a clear micellar solution with low viscosity (LC = $36 \mathrm{wt} \%)$. Therefore, the apparent solubility could be increased by a factor of $6 \times 10^{4}$. Notably, the loading efficiency (LE) did not change much while increasing the MT feed from 2 to $10 \mathrm{~g}$ $\mathrm{L}^{-1}$, ranging between $55 \%$ and $75 \%$. As stated previously, from a physiological perspective one possibility could be that, MT upon oral administration, because of its strong association to lipoproteins, enters the lipid transport pathway and MT bound to chylomicrons or their remnants are repeatedly exposed to hepatocytes resulting in higher rate of biotransformation and a much higher inactive metabolite concentration in blood. We postulate the administration of MT injectable formulation will render the optimal MT active metabolite concentration in blood by reducing its hepatic and extra hepatic metabolism. To the best of our knowledge, such high apparent MT aqueous solubility was never reported in the literature. Formulation experiments were performed with both polymer batches (P1 and P2) and no significant difference was observed in loading capacities (Tables S2 and S3, Supporting Information). In comparison to A-pBuOx-A, A-pBuOzi also gave good, somewhat lower LC of 27 wt $\%\left(\approx 3.7 \mathrm{~g} \mathrm{~L}^{-1}\right)$. In contrast, A-pPrOzi-A and A-pPrOx-A were much less effective in solubilizing MT with LC of $10 \mathrm{wt} \%$ $\left(\approx 1.3 \mathrm{~g} \mathrm{~L}^{-1}\right)$ and $5 \mathrm{wt} \%(\approx 0.5 \mathrm{~g} \mathrm{~L}$.) respectively. Also, the aromatic A-pBzOx-A was found less efficient than expected ${ }^{[50]}$ but was slightly better than A-pPrOx-A and A-pPrOzi-A with LC $\approx 16$ wt\% $\left(\approx 2 \mathrm{~g} \mathrm{~L}^{-1}\right)$ (Table S1, Supporting Information). Based on these results, we chose A-pBuOx-A based MT formulations for detailed physicochemical characterization and biological studies.

\subsubsection{Stability and Redispersion Studies of the Formulation}

To investigate the potential shelf-life of the formulations (A-pBuOx-A), the freshly prepared MT aqueous solutions were stored at ambient conditions containing the initial precipitate followed by the collection of samples at day $0,1,2,3,4,5$, and then at day 10, 20, 30. The formulations were centrifuged prior to each measurement. We have previously observed PTXbased A-pBuOx-A formulations have shown excellent stability up to several months ${ }^{[45,68]}$; however, other POx/PTX formulations were much less stable. ${ }^{[69]}$ The formulations with the MT feed of 2 and $4 \mathrm{~g} \mathrm{~L}^{-1}$ resulted in relatively stable formulations (Figure $2 \mathrm{~b}$ ). After $24 \mathrm{~h}$ only a minor loss in the LC was observed in both cases (11 to $10 \mathrm{wt} \%$ and 22 to $21 \mathrm{wt} \%$, respectively). However, after 30 days, the LC decreased to 3 and $10 \mathrm{wt} \%$, respectively. In case of higher MT feed of 6,8 , and $10 \mathrm{~g} \mathrm{~L}^{-1}$ (Figure $2 \mathrm{~b}$ ) a dramatic decrease in the LC (30 to 3, 35 to 2, and 36 to $4 \mathrm{wt} \%$, respectively) was observed within $24 \mathrm{~h}$. It is becoming more and more evident that drug molecules can also 
a)

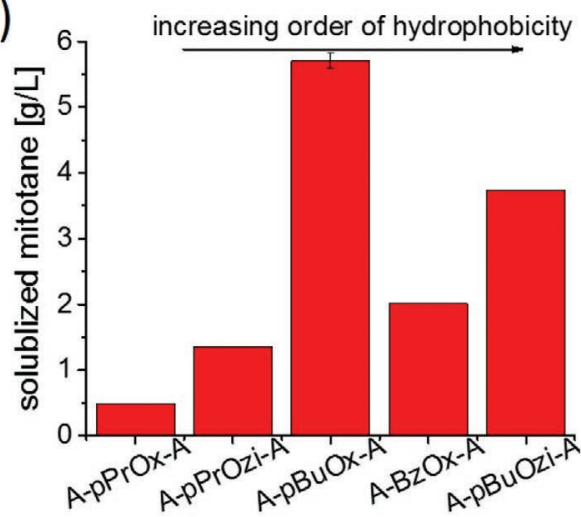

c)

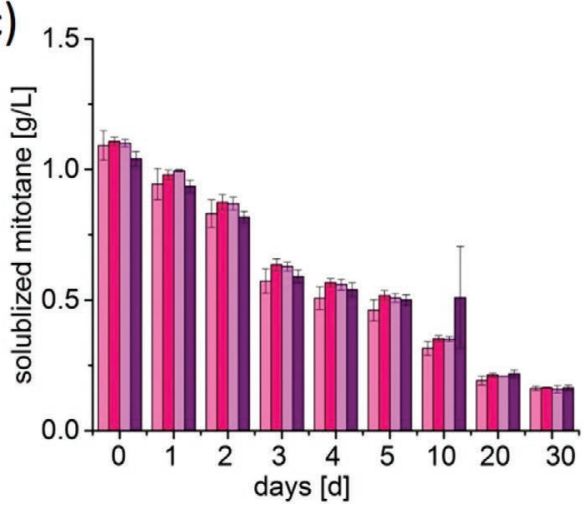

b)

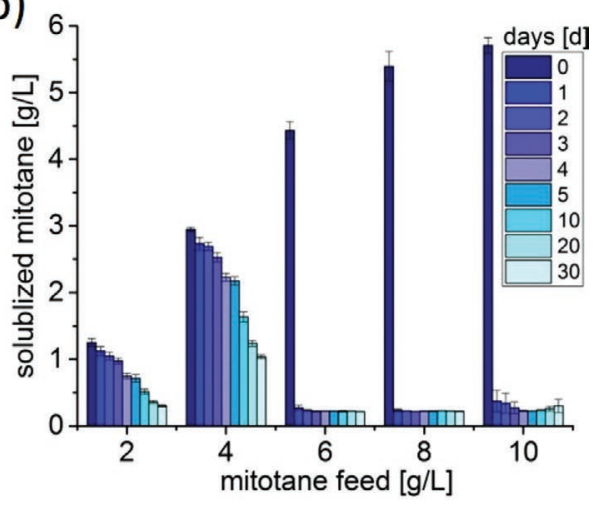

d)

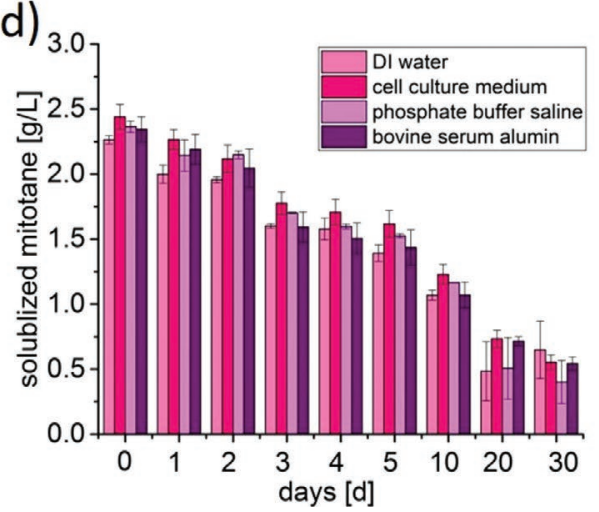

Figure 2. a) Maximum aqueous mitotane concentration obtained using different amphiphilic block copolymers (10 $\left.\mathrm{g} \mathrm{L}^{-1}\right)$ using the thin film method. Data is given as means \pm SD $(n=3)$ only for A-pBuOx-A based formulation. b) Long term stability of mitotane formulation in dependence of mitotane feed concentration (polymer $10 \mathrm{~g} \mathrm{~L}^{-1}$, mitotane $2-10 \mathrm{~g} \mathrm{~L}^{-1}$ ). Data is given as means $\pm \mathrm{SD}(n=3)$. Formulation stability after redispersion of A-pBuOxA: mitotane c) polymer to mitotane feed ratio of 10/2 and d) 10/4 formulation in different media, that is, deionized (DI) water, cell culture medium, phosphate buffer saline (PBS) of $\mathrm{pH} 7.4$ and PBS of $\mathrm{pH} 7.4$ with $40 \mathrm{~g} \mathrm{~L}^{-1}$ bovine serum albumin up to day 30 .

coordinate with the micellar corona. ${ }^{[70,71]}$ This drug-corona interaction can enable to ultra-high drug loading ${ }^{[71,72]}$ or lead to colloidal instability of the formulation. ${ }^{[49,73]}$ However, the drug corona interaction can also affect the morphology, ${ }^{[74]}$ endocytosis, ${ }^{[75,76]}$ or prolong supersaturation. ${ }^{[77]}$ Interestingly, for the POx/POzi nanoformulations the drug was found fully amorphous in the precipitate, which also contains polymer. ${ }^{[49,70]}$ It therefore appears that the micelles agglomerate and precipitate with the still amorphous drug embedded. However, the extremely rapid precipitation observed here at polymer/drug feed $\geq 10 / 6 \mathrm{~g} \mathrm{~L}^{-1}$ suggests at a different mechanism. Therefore, we investigated the precipitate after $24 \mathrm{~h}$ from a formulation with polymer/drug feed of $10 / 8 \mathrm{~g} \mathrm{~L}^{-1}$ by differential scanning calorimetry (DSC). The first heating cycle clearly showed the melting peak of MT at $78{ }^{\circ} \mathrm{C}$ (Figure S10, Supporting Information), indicative of $\mathrm{MT}$ rapid crystallization from the formulation above a critical feed of $>10 / 4 \mathrm{~g} \mathrm{~L}^{-1}$. In contrast, at $10 / 4$, A-pBuOx-A acts as a rather effective crystallization inhibitor. This could be very promising for improving the bioavailability after oral administration.

Formulations with limited stability in an aqueous environment may be stored in lyophilized state. In this case, redispersibility is a key issue. Here, the A-pBuOx-A based MT formulation with the drug feed of 2 and $4 \mathrm{~g} \mathrm{~L}^{-1}$ were lyophilized and redispered in different media (Figure 2c,d). The lyophilized formulations were stored for 7 days at ambient conditions followed by redispersion in DI water, cell culture medium, PBS and PBS with $40 \mathrm{~g} \mathrm{~L}^{-1} \mathrm{BSA}$. Upon redispersion with DI water, initially a minor decrease in LC (11 to 10 and 22 to $18 \mathrm{wt} \%$ for 2 and $4 \mathrm{~g} \mathrm{~L}^{-1}$ MT feed, respectively) was observed. A similar pattern was observed in case of other redispersion mediums. However, long-term stability after redispersion followed a similar pattern as that for freshly prepared formulation showing time dependent gradual decrease in LC. It can be concluded that A-pBuOx-A based MT formulations should be stored as lyophilized powder and used freshly after redispersion. Even though this was not systematically studied at this point, the lyophilized powders seem to be quite stable at ambient conditions. No deterioration of re-dispersibility was observed over the time course of this study. Of course, these preliminary studies to not exclude the possibility to extend shelf-life, for example, by addition of other excipients.

\subsubsection{Polymer Drug Compatibility Evaluation by Hansen Solubility Parameters}

The physicochemical compatibility between an active pharmaceutical ingredient and the drug delivery system is believed to be a key factor in the formulation development process 
Table 2. Hansen solubility parameters of mitotane and core forming blocks of the ABA triblock copolymers.

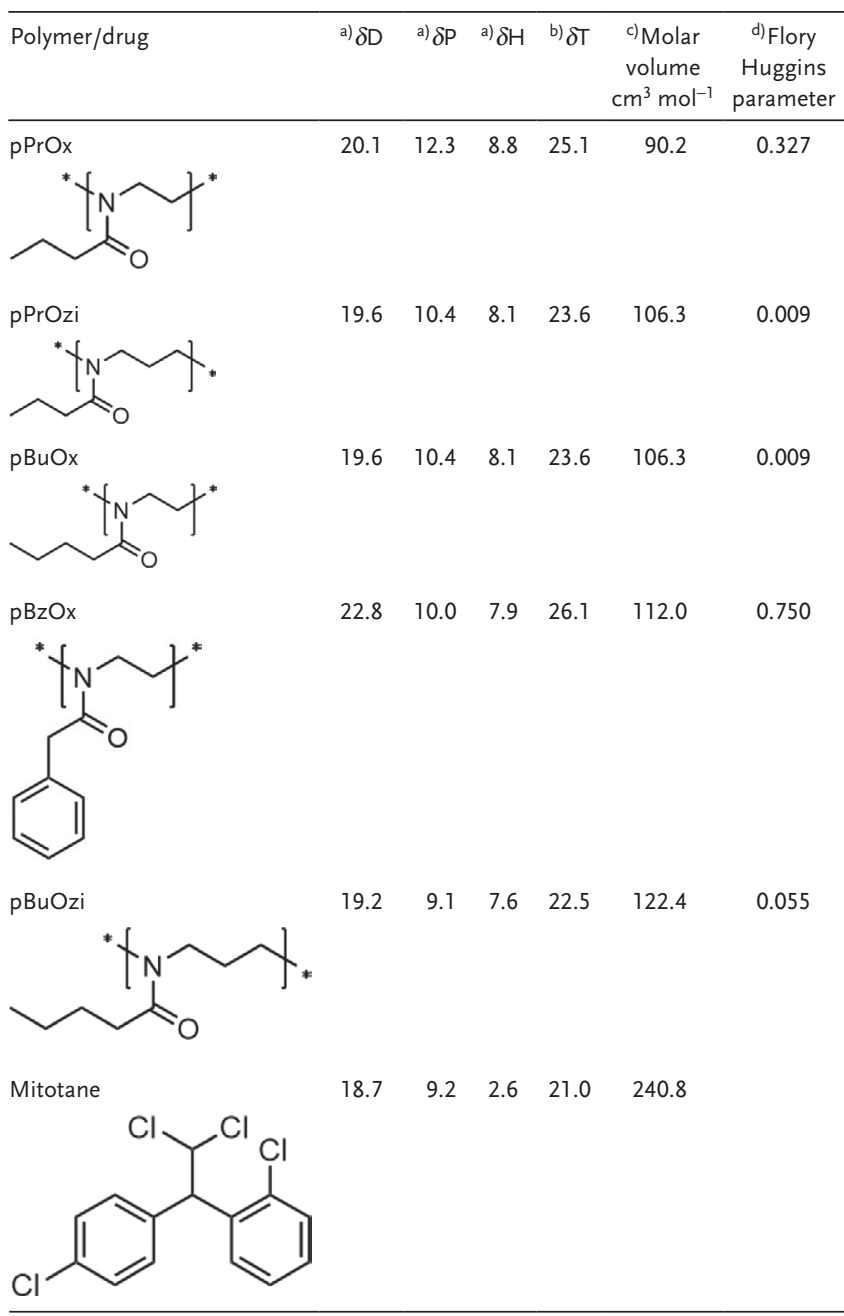

a) Calculated by Hoftyzer and Van Krevelen's method, Equations (4), (5), and (6); ${ }^{b)}$ calculated by Equations (2) and (3); c)calculated by Fedor's method; ${ }^{d)}$ calculated by Equation (1).

to determine the suitability of the drug delivery system. Considering the plethora of drugs with unique physicochemical properties, a universal carrier for all the drugs seems impossible. ${ }^{[78]}$ There are various ways to assess the drug polymer compatibility ${ }^{\left[{ }^{[9-82]}\right.}$ which are thought to help to select a suitable carrier for a specific drug in time and cost effective manner. The extent of compatibility between MT and POx based carriers was calculated by the Hansen solubility parameter (HSP) (Table 2)..$^{[83,84]}$ For the further details on HSPs calculations please refer to the Supporting Information (Tables S4-S5, Supporting Information).

The extent of compatibility between MT and the core forming blocks was estimated by Flory-Huggin's interaction parameters $\left(\chi_{d p}\right)$. The lower the value of $\chi_{d p}$ the better the polymer/drugs compatibility. Based on the calculated $\chi_{d p}$, MT compatibility with five of selected amphiphiles was in the following order $\mathrm{pBuOx}=\mathrm{pPrOzi}>\mathrm{pBuOzi}>\mathrm{pPrOx}>\mathrm{pBzOx}$. Interestingly, the core forming block pBuOx and pPrOzi are suggested to be best solubilizers for the MT. Being based on group contribution methods, the calculated solubility parameters of $\mathrm{pBuOx}$ and pPrOzi, which are structural isomers, yielded identical solubility parameter values and thus, compatibility for the drug MT. Experimentally, however, strong contrast in the solubilization capacities were found, similar to the situation reported for other drugs. ${ }^{[4]}$ Interestingly, pBzOx was suggested to be the least compatible polymer, even though it features the aromatic system. It is apparent that the experimental results are only partially consistent with the calculated compatibility profile between MT and core forming blocks. It seems that the correct assignment of the best solubilizer, $\mathrm{pBuOx}$ is more coincidental and does not indicate that HSP can correctly predict compatibilities in the present system.

\subsubsection{Physicochemical Characterization of MT Nanoformulations}

A-pBuOx-A based MT nanoformulations were characterized using FT-IR, DSC, XRD, and DLS (polymer/drug 10/2 $\mathrm{g} \mathrm{L}^{-1}$ ). FT-IR spectroscopy (Figure 3a) of lyophilized formulation in comparison with the physical mixture, pure drug, and pure polymer was performed to characterize potential interactions between MT and polymer. Pure MT is characterized by a number of sharp signals, with particular strong signals in the range of $700-800 \mathrm{~cm}^{-1}$, which are attributed to the $-\mathrm{C}-\mathrm{Cl}$ stretching vibration. MT also exhibited a characteristic signal at $1490 \mathrm{~cm}^{-1}$, which is attributed to $-\mathrm{C}=\mathrm{C}-$ aromatic stretch. While in the physical mixture these signals can still be observed, they completely vanished in the case of nanoformulation. The broader signal at $1630 \mathrm{~cm}^{-1}$ is attributed to the stretching and bending vibration of carbonyl stretch and no noticeable change was observed between the spectra of physical mixture and nanoformulation. Overall, IR suggest very significant interaction between MT and the polymer. As the sharp signals of MT do not shift but significantly broaden to the point of becoming indiscernible these interactions are presumed to be versatile and undefined.

In order to investigate the thermal behavior of MT nanoformulations, DSC (Figure 3b) was conducted for pure polymer, pure drug, physical mixture, and the lyophilized nanoformulation. The thermogram of pure drug and its physical mixture with polymer showed an endothermic peak at 80 and $78{ }^{\circ} \mathrm{C}$, respectively, which represents the characteristic melting peak of MT. The disappearance of the melting endothermic peak of the drug in the nanoformulation shows that MT is fully amorphous in the lyophilized nanoformulation. Therefore, the lyophilized nanoformulation can be considered a solid amorphous dispersion of MT in A-pBuOx-A.

For further analysis, pure polymer, pristine drug, physical mixture, and the lyophilized micellar formulation were analyzed by powder-XRD (Figure 3c). The XRD spectra of the pristine MT shows numerous reflexes in the $2 \Theta$ range of 5 to $40^{\circ}$ corresponding to the crystalline nature of MT. The identical spectrum was observed for physical mixture of drug with polymer. In contrast, no signs of crystallinity were observed in case of lyophilized nanoformulation even after 15 days of storage at ambient conditions, confirming the amorphous nature of MT 

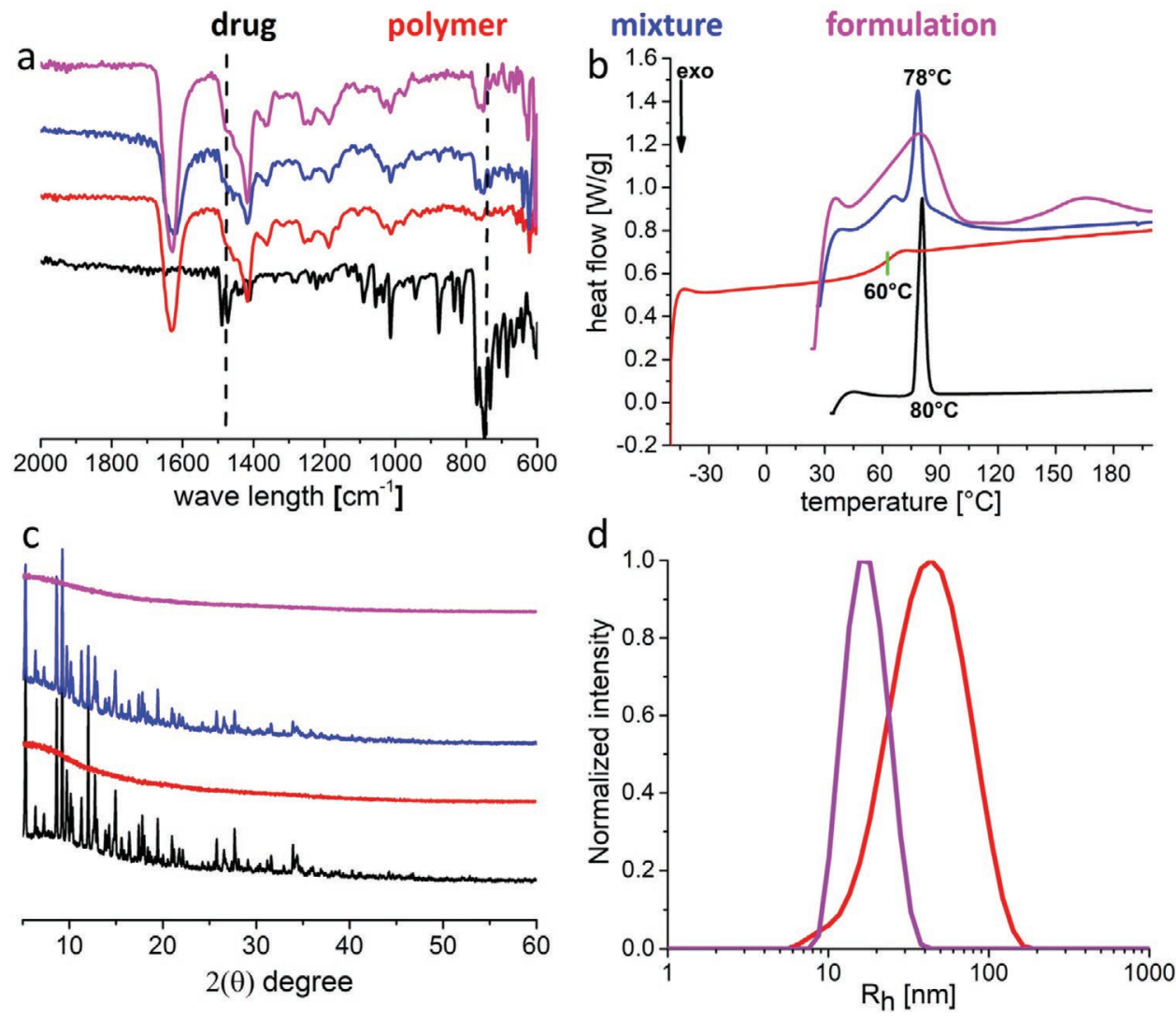

Figure 3. a) FT-IR spectra, b) DSC thermograms (first heating cycle for drug, mixture, formulation, and second heating cycle for pure polymer is shown) and c) XRD spectra of pure drug (black), polymer (red), physical mixture of drug, and polymer (blue) and nanoformulation (purple) for a polymer to drug ratio $10 / 2(\mathrm{w} / \mathrm{w})$. d) The size distribution by intensity of pure polymer $\left(10 \mathrm{~g} \mathrm{~L}^{-1}\right)$ (red) and mitotane formulation (10/2 w/w) (purple) in deionized water after filtration through $0.45 \mu \mathrm{m}$ PVDF filter.

in the nanoformulation. After redispersion, the hydrodynamic radii $\left(R_{\mathrm{h}}\right)$ of the micelles was estimated by zeta sizer (Figure $3 \mathrm{~d}$ and Figure S11, Supporting Information) showing $R_{\mathrm{h}} \approx 40 \mathrm{~nm}$ for the pure polymer and $R_{\mathrm{h}} \approx 20 \mathrm{~nm}$ for the MT-encapsulated micelles.

\subsection{Cell Studies}

\subsubsection{Cytocompatibility Studies on HepG2 and NCl-H295 Cell Lines}

When it comes to the in vivo administration, the safety of the polymer excipients is of great interest. Even though cytocompatibility of POx based amphiphiles has been established several times, ${ }^{[46,58,85]}$ cytocompatibility of the presently employed polymer was investigated in HepG2 and NCI-H295 cell lines using WST1 and CellTiter Glo assay (which reflects ATP content) after treatment with polymer solution at different concentrations for 6 and $24 \mathrm{~h}$. We investigated both polymer batches, that is, P1 and P2 by WST1 assay in NCI-H295R and HepG2 cell lines at concentrations of up to 100 and $50 \mathrm{~g} \mathrm{~L}^{-1}$ for P2 and P1, respectively (Figure 4a,b and Figure S12, Supporting Information). No sign of cytotoxicity was observed and cell viability remained above $95 \%$ in all cases indicating its excellent cytocompatibility. Similar results were obtained using the CellTiter Glo assay (Figure 4c and Figure S12, Supporting Information).

\subsubsection{In Vitro 2D and 3D Cytotoxicity Studies of Nanoformulations on $\mathrm{NCl}-\mathrm{H} 295$ Cell Lines}

The cytotoxicity of MT in EtOH and micellar formulation was determined by CellTiter Glo assay in both 2D (monolyer) and 3D (spheroids) NCI-H295R cell lines, for 24 and $48 \mathrm{~h}$. In all the cases dose dependent cytotoxicity was observed.

For the monolayer culture, there was no significant difference in cytotoxicity between MT in EtOH and MT in micelles $(p>0.05)$ upon $24 \mathrm{~h}$ incubation (Figure 5a). The $\mathrm{IC}_{50,24 \mathrm{~h}}$ were 15 and $19 \mu \mathrm{M}$ for MT in EtOH and micelles, respectively, which corresponds well with values found in the literature $\left(\mathrm{IC}_{50,24 \mathrm{~h}}=\right.$ $15 \mu_{\mathrm{M}}{ }^{[18]}$ The cell viability was less than $3 \%$ at $50 \mu \mathrm{M}$ MT concentration (either in EtOH or micelles) consistent with the previous reports by Silveira et al. and others. ${ }^{[86,87]}$ Prolonged incubation had no effect on $\mathrm{IC}_{50}$ values $\left(\mathrm{IC}_{50,48 \mathrm{~h}}=15\right.$ and $18 \mu \mathrm{M}$ for MT in EtOH and micelles, respectively ( $p>0.05)$, Figure $5 b)$.

There is growing evidence that cancerous cells grown as spheroids do more accurately mimic the 3D tumor microenvironment when compared to monolayer cultures. ${ }^{[88]}$ Besides 


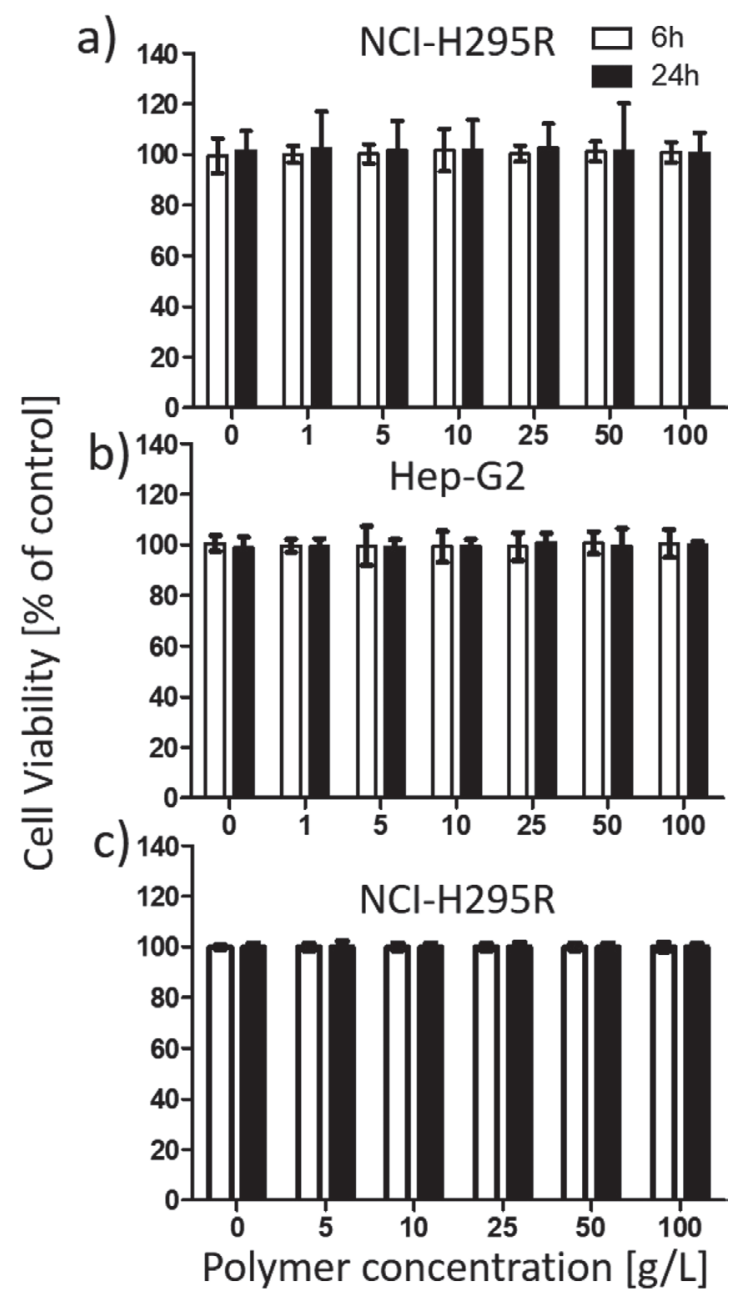

Figure 4. Cell viability of A-pBuOx-A (P2) in a) $\mathrm{NCl}-\mathrm{H} 295$ and b) $\mathrm{HepC} 2$ cell line by WST1 assay and c) $\mathrm{NCl}-\mathrm{H} 295$ cell line by CellTiter Glo assay after $6 \mathrm{~h}$ (white) and $24 \mathrm{~h}$ (black) incubation. Experiments were performed as duplicate (in case of WST1 assay) and as single experiment for the CellTiter Glo assay with $n=8$ technical replicates. Data is expressed as means \pm standard deviation.

activation of cell-cell and cell-matrix interactions, spheroids also simulate some in vivo tumor characteristics such as dormancy, hypoxia, and activation of anti-apoptotic signaling. After $96 \mathrm{~h}$ of incubation, we obtained single, uniformly sized, and dense spheroids of NCI-H295R cells (Figure S14, Supporting Information). ${ }^{[87]}$ In general, when compared to $2 \mathrm{D}$ monolayer cells, cancer cells are less sensitive to drugs when analyzed in spheroids. This could be attributed to hypoxia and tight cellcell interactions in spheroids leading to poor permeability, among other factors. ${ }^{[89]}$ Accordingly, we used range of higher concentration $(50-200 \mu \mathrm{M}$ MT). Important to note, the MT in EtOH dilution (prepared in cell culture medium) at $200 \mu \mathrm{M}$ turned milky, whereas A-pBuOx-A based MT micelles remained a clear solution. This suggests MT emulsion or precipitation and it follows that such high concentrations are feasible in vivo only when using a suitable drug carrier. In spheroids, we expectedly observed resistance to pharmacotherapy with $\mathrm{IC}_{50,24 \mathrm{~h}}$ values determined at 75 and $65 \mu \mathrm{m}$ for $\mathrm{MT}$ in $\mathrm{EtOH}$ and micelles, respectively (Figure 5c), whereas $\mathrm{IC}_{50}$ was 15 and $19 \mu \mathrm{M}$ in monolayer cultures. Cell viability was drastically reduced at $100 \mu \mathrm{M}(<30 \%)$ and $150 \mu \mathrm{M}(<7 \%)$ MT concentration either in ethanol or micelles. Almost no cells survived at $200 \mu \mathrm{M}$ MT concentration (Figure 5c), irrespective whether MT was administered in $\mathrm{EtOH}$ or as nanoformulation.

Interesting to note, in case of spheroids, incubation time did affect cell viability. The $\mathrm{IC}_{50,48 \mathrm{~h}}$ was found to be 47 and $43 \mu \mathrm{m}$ for MT in ethanol and micelles, respectively (Figure $5 \mathrm{~d}$ ). Data reported by Silveira et al. suggest that $72 \mathrm{~h}$ incubation time of NCI-H295 cell spheroids ${ }^{[8]}$ led to 15 and $26 \%$ cell viability at 30 and $50 \mu \mathrm{M}$ MT concentration (dissolved in ethanol), respectively. However, it is possible that different strains of NCI-H295 cells and culture conditions may affect the properties of spheroids cultivated in different laboratories.

When comparing the increase of $\mathrm{IC}_{50}$ values from 2D monolayer cultures to $3 \mathrm{D}$ spheroids we observed a more pronounced increase of $\mathrm{IC}_{50}$ values for MT in EtOH compared to our nanoformulation. At $24 \mathrm{~h}$ incubation, the increase was fivefold when using EtOH but only 3.4-fold in case of the nanoformulation. At $48 \mathrm{~h}$, the $\mathrm{IC}_{50}$ values increased $3.1(\mathrm{EtOH})$ and $2.4(\mathrm{~A}-\mathrm{pBuOx}-\mathrm{A})$ fold. This could potentially be attributed to a better penetration of the drug into the spheroids when nanoformulated, but this hypothesis will need to be tested thoroughly.

\section{Conclusion}

Motivated by the poor aqueous solubility $\left(0.1 \mathrm{mg} \mathrm{L}^{-1}\right)$, extremely high daily dosage (up to $6 \mathrm{~g}$ per day in divided doses) and unfavorable pharmacokinetic profile of the adrenolytic drug mitotane (MT), we attempted the development of MT loaded micelles which may enable both improved oral administration and an injectable formulation to overcome critical clinical limitations. A poly(2-oxazoline) (POx) based formulation $\left(\mathrm{pMeO}_{35}-\mathrm{pBuOx}_{20}\right.$ $\mathrm{pMeOx}_{35}$ ) was capable to increase the aqueous solubility of MT to around $6 \mathrm{~g} \mathrm{~L}^{-1}(\mathrm{LC} \approx 36 \mathrm{wt} \%)$. To the best of our knowledge, such high MT water solubility has never been reported in the literature. Various instrumental techniques confirmed the development of a stable nanoformulation. This formulation can be stored as lyophilized powder ready for re-dispersion. The polymer excipient was proven to be highly cytocompatible even at extremely high concentrations of $100 \mathrm{~g} \mathrm{~L}^{-1}$ in NCI-H295R and HepG2 cell lines (cell viability $>95 \%$ ). The obtained $\mathrm{IC}_{50}$ values in conventional 2D monolayer cell cultures were comparable for MT dissolved in EtOH and micelles (15 and $19 \mu \mathrm{M}$, respectively) while in the case of 3D tumor spheroids higher doses were needed to obtained cytotoxic effects, which confirms an increased resistance of the tumor cells cultured in $3 \mathrm{D}$. The $\mathrm{IC}_{50}$ at $24 \mathrm{~h}$ values were 75 and $65 \mu \mathrm{m}$ for $\mathrm{MT}$ in EtOH and micelles, respectively. Time dependent decrease in $\mathrm{IC}_{50}$ after $48 \mathrm{~h}$ incubation was observed in case of spheroids $(47$ and $43 \mu \mathrm{m}$ for MT in EtOH and micelles, respectively) which points to a diffusion limited process of tissue penetrance. It stands to reason that this nanoformulation, for the first time, might allow the parenteral administration of MT, which will help to alleviate not only the side effects associated with the use of high dose oral therapy of $6 \mathrm{~g}$ per day but also circumventing the variable oral absorption resulting in more predictable therapeutic plasma concentration and better 


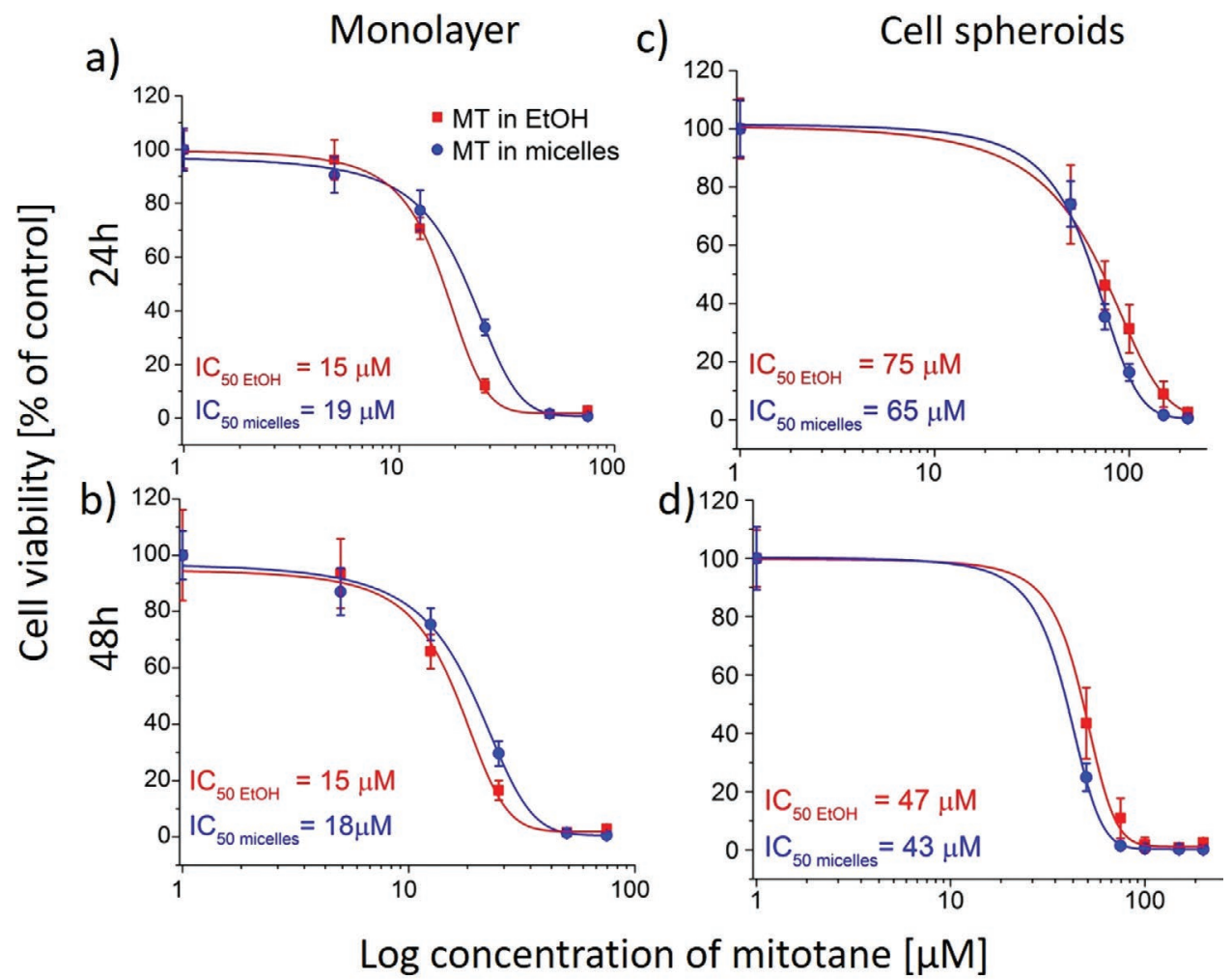

Figure 5. Cell viability and corresponding $\mathrm{IC}_{50}$ values of mitotane dissolved in ethanol (red) and as micelles formulation (blue) in $\mathrm{NCl}-\mathrm{H} 295 \mathrm{R}$ monolayer after incubation for a) 24 and b) $48 \mathrm{~h}$ and 3D tumor spheroids c) $24 \mathrm{~h}$ and d) $48 \mathrm{~h}$ ) as determined by CellTiterGlo assay. Monolayer and tumor spheroids were treated with the range of mitotane concentrations dissolved in ethanol and as A-pBuOx-A nanoformulation. All the values are average of replicates expressed relative to cell viability values in control cells normalized to $100 \%$. Data points represent average of $n=3$ experiments with eight technical replicates per mitotane concentration for each experiment \pm standard deviation.

pharmacokinetic profile. However, the safety and tolerability of this injectable formulation remain to be demonstrated.

\section{Supporting Information}

Supporting Information is available from the Wiley Online Library or from the author.

\section{Acknowledgements}

This work was supported by Deutsche Forschungsgemeinschaft (DFG), German Research Foundation Project no. 398461692 to R.L. and 314061271 - TRR205 and 237292849 to M.K). Moreover, Malik Salman Haider is grateful to the Higher education commission of Pakistan and German academic exchange services (HEC-DAAD Pakistan) for the award of Ph.D. scholarship. The authors thank Lukas Hahn for providing A-pBzOx-A triblock copolymer as well as André Muthig and Thomas Lorson technical support. Also, the authors are indebted to Prof. AnnChristin Pöppler for measuring DOSY NMR spectra of $\mathrm{Pl}$ and very valuable discussions.

\section{Conflict of Interest}

R.L. is listed as co-inventor of several patents pertinent to the present contribution and is co-founder of Delaqua Pharmaceutical Inc. intending commercial development of poly(2-oxazoline)-based drug delivery systems.

\section{Keywords}

adrenocortical carcinoma, amphiphilic block copolymer, NCl-H295R, poly(2-oxazoline), solubility enhancement

Received: May 22, 2019

Revised: August 16, 2019

Published online: October 9, 2019

[1] B. Allolio, M. Fassnacht, J. Clin. Endocrinol. Metabol. 2006, 91, 2027.

[2] E. Kebebew, E. Reiff, Q. Y. Duh, O. H. Clark, A. McMillan, World J. Surg. 2006, 30, 872 .

[3] T. M. Kerkhofs, R. H. Verhoeven, J. M. Van der Zwan, J. Dieleman, M. N. Kerstens, T. P. Links, L. V. Van de Poll Franse, H. R. Haak, Europ. J. Cancer 2013, 49, 2579.

[4] I. Veytsman, L. Nieman, T. Fojo, J. Clin. Oncol. 2009, 27, 4619.

[5] S. Sbiera, E. Leich, G. Liebisch, I. Sbiera, A. Schirbel, L. Wiemer, S. Matysik, C. Eckhardt, F. Gardill, A. Gehl, Endocrinology 2015, 156, 3895.

[6] S. Hescot, L. Amazit, M. Lhomme, S. Travers, A. DuBow, S. Battini, G. Boulate, I. J. Namer, A. Lombes, A. Kontush, Oncotarget 2017, 8, 109924. 
[7] S. Hescot, A. Slama, A. Lombes, A. Paci, H. Remy, S. Leboulleux, R. Chadarevian, S. Trabado, L. Amazit, J. Young, Endocrine-Related Cancer 2014, 20, 371.

[8] A. Berruti, E. Baudin, H. Gelderblom, H. Haak, F. Porpiglia, M. Fassnacht, G. Pentheroudakis, Ann. Oncol. 2012, 23, vii131.

[9] I. Bourdeau, J. M. Feder, A. Lacroix, Current Opinion Endocrinol. Diabetes Obesity 2013, 20, 192.

[10] M. Fassnacht, M. Kroiss, B. Allolio, J. Clin. Endocrinol. Metabol. 2013, 98, 4551.

[11] T. Else, A. C. Kim, A. Sabolch, V. M. Raymond, A. Kandathil, E. M. Caoili, S. Jolly, B. S. Miller, T. J. Giordano, G. D. Hammer, Endocrine Rev. 2014, 35, 282.

[12] M. Fassnacht, O. Dekkers, T. Else, E. Baudin, A. Berruti, R. R. De Krijger, H. Haak, R. Mihai, G. Assie, M. Terzolo, Eur. J. Endocrinol. 2018, 179, G1.

[13] E. Baudin, G. Pellegriti, M. Bonnay, A. Penfornis, A. Laplanche, G. Vassal, M. Schlumberger, Cancer 2001, 92, 1385.

[14] M. Terzolo, A. Baudin, A. Ardito, M. Kroiss, S. Leboulleux, F. Daffara, P. Perotti, R. Feelders, B. Zaggia, S. De Francia, Eur. J. Endocrinol. 2013, 169, 263.

[15] I. G. Hermsen, M. Fassnacht, M. Terzolo, S. Houterman, J. den Hartigh, S. Leboulleux, F. Daffara, A. Berruti, R. Chadarevian, M. Schlumberger, J. Clin. Endocrinol. Metabol. 2011, 96, 1844.

[16] F. Megerle, W. Herrmann, W. Schloetelburg, C. L. Ronchi, A. Pulzer, M. Quinkler, F. Beuschlein, S. Hahner, M. Kroiss, M. Fassnacht, J. Clin. Endocrinol. Metabol. 2018, 103, 1686.

[17] T. Kerkhofs, E. Baudin, M. Terzolo, B. Allolio, R. Chadarevian, H. Mueller, B. Skogseid, S. Leboulleux, F. Mantero, H. Haak, J. Clin. Endocrinol. Metabol. 2013, 98, 4759.

[18] M. Kroiss, D. Plonné, S. Kendl, D. Schirmer, C. L. Ronchi, A. Schirbel, M. Zink, C. Lapa, H. Klinker, M. Fassnacht, Eur. J. Endocrinol. 2016, 174, 343 .

[19] U. Arshad, M. Taubert, M. Kurlbaum, S. Frechen, S. Herterich, F. Megerle, S. Hamacher, M. Fassnacht, U. Fuhr, M. Kroiss, Eur. J. Endocrinol. 2018, 179, 287.

[20] S. Hescot, A. Paci, A. Seck, A. Slama, S. Viengchareun, S. Trabado, S. Brailly Tabard, A. Al Ghuzlan, J. Young, E. Baudin, Hormon Cancer 2014, 5, 312.

[21] V. Sreif, J. Sinsheimer, J. Ward, D. Schteingart, J. Pharm. Sci. 1974 63, 1730.

[22] A. Mornar, M. Sertić, N. Turk, B. Nigović, M. Koršić, Biomed. Chromatogr. 2012, 26, 1308 .

[23] N. P. van Erp, H. J. Guchelaar, B. A. Ploeger, J. A. Romijn, J. den Hartigh, H. Gelderblom, Eur. J. Endocrinol. 2011, 164, 621.

[24] M. Kroiss, M. Quinkler, W. K. Lutz, B. Allolio, M. Fassnacht, Clin. Endocrinol. 2011, 75, 585.

[25] V. Chortis, A. E. Taylor, P. Schneider, J. W. Tomlinson, B. A. Hughes, D. M. O'neil, R. Libé, B. Allolio, X. Bertagna, J. Bertherat, J. Clin. Endocrinol. Metabol. 2013, 98, 161.

[26] D. Theile, W. E. Haefeli, J. Weiss, Endocrine 2015, 49, 842.

[27] J. W. Biggar, R. L. Riggs, Hilgardia 1974, 42, 383.

[28] R. Takano, K. Furumoto, K. Shiraki, N. Takata, Y. Hayashi, Y. Aso, S. Yamashita, Pharm. Res. 2008, 25, 2334.

[29] H. v. Slooten, A. V. Seters, D. Smeenk, A. Moolenaar, Cancer Chemother. Pharmacol. 1982, 9, 85

[30] D. Attivi, I. Ajana, A. Astier, B. Demore, S. Gibaud, Drug Dev. Ind. Pharm. 2010, 36, 421.

[31] F. Battung, E. Hassan, L. Sansoe, US8486445B2 2013

[32] E. Hassan, WO2012071043A1 2015.

[33] D. Gebhardt, A. Moolenaar, A. V Seters, E. Van Der Velde, J. G. Leuven, Cancer Chemother. Pharmacol. 1992, 29, 331

[34] R. C. Pohland, R. E. Counsell, Toxicol. Appl. Pharmacol. 1985, 77, 47.

[35] S. Hescot, A. Seck, M. Guerin, F. Cockenpot, T. Huby, S. Broutin, J. Young, A. Paci, E. Baudin, M. Lombès, J. Clinical Endocrinol. Metabol. 2015, 100, 2890.
[36] V. Maher, P. Trainer, A. Scoppola, J. Anderson, G. Thompson, G. Besser, Q. J. Med 1992, 84, 671.

[37] N. Nishiyama, K. Kataoka, Pharmacol. Ther. 2006, 112, 630.

[38] K. Kataoka, A. Harada, Y. Nagasaki, Adv. Drug Delivery Rev. 2012, 64, 37.

[39] H. Cabral, N. Nishiyama, K. Kataoka, J. Controlled Release 2007, 121, 146

[40] J. Logie, A. N. Ganesh, A. M. Aman, R. S. Al awar, M. S. Shoichet, Biomaterials 2017, 123, 39.

[41] H. Cabral, K. Kataoka, J. Controlled Release 2014, 190, 465.

[42] E. Vlassi, A. Papagiannopoulos, S. Pispas, Eur. Polym. J. 2017, 88, 516.

[43] R. Hoogenboom, Eur. Polym. J. 2017, 88, 448

[44] T. Lorson, M. M. Lübtow, E. Wegener, M. S. Haider, S. Borova, D. Nahm, R. Jordan, M. Sokolski-Papkov, A. V. Kabanov, R. Luxenhofer, Biomaterials 2018, 178, 204.

[45] Y. Han, Z. He, A. Schulz, T. K. Bronich, R. Jordan, R. Luxenhofer, A. V. Kabanov, Mol. Pharmaceutics 2012, 9, 2302.

[46] R. Luxenhofer, G. Sahay, A. Schulz, D. Alakhova, T. K. Bronich, R. Jordan, A. V. Kabanov, J. Controlled Release 2011, 153, 73.

[47] H. Witte, W. Seeliger, Justus Liebigs Annalen der Chemie 1974, 1974, 996

[48] M. M. Lübtow, L. Hahn, M. S. Haider, R. Luxenhofer, J. Am. Chem. Soc. 2017, 139, 10980

[49] M. M. Lübtow, L. Keßler, A. Appelt Menzel, T. Lorson, N. Gangloff, M. Kirsch, S. Dahms, R. Luxenhofer, Macromol. Biosci. 2018, 18, 1800155.

[50] L. Hahn, M. M. Lübtow, T. Lorson, F. Schmitt, A. AppeltMenzel, R. Schobert, R. Luxenhofer, Biomacromolecules 2018, 19, 3119 .

[51] K. Letchford, R. Liggins, H. Burt, J. Pharm. Sci. 2008, 97, 1179

[52] R. F. Fedors, Polym. Eng. Sci. 1974, 14, 147.

[53] A. F. Gazdar, H. K. Oie, C. H. Shackleton, T. Chen, T. J. Triche, C. E. Myers, G. P. Chrousos, M. F. Brennan, C. Stein, R. V. La Rocca, Cancer Res. 1990, 50, 5488.

[54] R. Luxenhofer, M. Bezen, R. Jordan, Macromol. Rapid Commun. 2008, 29, 1509

[55] N. Zhang, S. Huber, A. Schulz, R. Luxenhofer, R. Jordan, Macromolecules 2009, 42, 2215.

[56] B. Guillerm, S. Monge, V. Lapinte, J. J. Robin, Macromol. Rapid Commun. 2012, 33, 1600

[57] N. Zhang, R. Luxenhofer, R. Jordan, Macromol. Chem. Phys. 2012, 213,973

[58] R. Luxenhofer, A. Schulz, C. Roques, S. Li, T. K. Bronich, E. V. Batrakova, R. Jordan, A. V. Kabanov, Biomaterials 2010, 31, 4972.

[59] R. Luxenhofer, Nanomedicine 2015, 10, 3109

[60] Z. He, A. Schulz, X. Wan, J. Seitz, H. Bludau, D. Y. Alakhova, D. B. Darr, C. M. Perou, R. Jordan, I. Ojima, J. Controlled Release 2015, 208, 67.

[61] Y. Milonaki, E. Kaditi, S. Pispas, C. Demetzos, J. Polym. Sci., Part A: Polym. Chem. 2012, 50, 1226

[62] X. Wan, Y. Min, H. Bludau, A. Keith, S. S. Sheiko, R. Jordan, A. Z. Wang, M. Sokolsky Papkov, A. V. Kabanov, ACS Nano 2018, 12, 2426

[63] S. Lv, Y. Wu, K. Cai, H. He, Y. Li, M. Lan, X. Chen, J. Cheng, L. Yin, J. Am. Chem. Soc. 2018, 140, 1235.

[64] S. Wieczorek, D. Remmler, T. Masini, Z. Kochovski, A. K. Hirsch, H. G. Börner, Bioconjugate Chem. 2017, 28, 760.

[65] J. Ding, L. Chen, C. Xiao, L. Chen, X. Zhuang, X. Chen, ChemComm 2014, 50, 11274

[66] Y. Shi, M. J. van Steenbergen, E. A. Teunissen, L. Novo, S. Gradmann, M. Baldus, C. F. van Nostrum, W. E. Hennink, Biomacromolecules 2013, 14, 1826. 
[67] P. Severino, E. B. Souto, S. C. Pinho, M. H. Santana, Pharm. Dev. Technol. 2013, 18, 577.

[68] A. Schulz, S. Jaksch, R. Schubel, E. Wegener, Z. Di, Y. Han, A. Meister, J. r. Kressler, A. V. Kabanov, R. Luxenhofer, ACS Nano 2014, 8, 2686.

[69] Y. Seo, A. Schulz, Y. Han, Z. He, H. Bludau, X. Wan, J. Tong, T. K. Bronich, M. Sokolsky, R. Luxenhofer, Polym. Adv. Technol. 2015, 26, 837.

[70] J. Wiest, M. Saedtler, B. Böttcher, M. Grüne, M. Reggane, B. Galli, U. Holzgrabe, L. Meinel, Mol. Pharmaceutics 2018, 15, 4470.

[71] A. C. Pöppler, M. M. Lübtow, J. Schlauersbach, J. Wiest, L. Meinel, R. Luxenhofer, ChemRxiv 2019, https://doi.org/10.26434/chemrxiv.8943251.v1.

[72] M. M. Lübtow, L. C. Nelke, J. Seifert, J. Kühnemundt, G. Sahay, G. Dandekar, S. L. Nietzer, R. Luxenhofer, J. Controlled Release 2019, 303, 162.

[73] M. M. Lübtow, M. S. Haider, M. Kirsch, S. Klisch, R. Luxenhofer, Biomacromolecules 2019, 20, 3041.

[74] C. Cao, J. Zhao, F. Chen, M. Lu, Y. Y. Khine, A. Macmillan, C. J. Garvey, M. H. Stenzel, Chem. Mater. 2018, 30, 5227.

[75] C. Cao, J. Zhao, M. Lu, C. J. Garvey, M. H. Stenzel, Biomacromolecules 2019, 20, 1545.

[76] M. Callari, P. L. De Souza, A. Rawal, M. H. Stenzel, Angew. Chem. 2017, 129, 8561
[77] Z. Li, T. I. Lenk, L. J. Yao, F. S. Bates, T. P. Lodge, Macromolecules 2018, 51, 540 .

[78] J. Liu, Y. Xiao, C. Allen, J. Pharm. Sci. 2004, 93, 132.

[79] C. Wu, J. W. McGinity, Int. J. Pharm. 1999, 177, 15.

[80] R. Nair, N. Nyamweya, S. Gönen, L. M. Miranda, S. Hoag, Int. J. Pharm. 2001, 225, 83.

[81] S. Y. Lin, C. J. Lee, Y. Y. Lin, J. Controlled Release 1995, 33, 375.

[82] B. Hossin, K. Rizi, S. Murdan, Eur. J. Pharm. Biopharm. 2016, 102, 32.

[83] C. M. Hansen, Hansen Solubility Parameters: a User's Handbook, CRC press, Boca Raton 2007.

[84] A. F. Barton, CRC Handbook of Solubility Parameters and other Cohesion Parameters, Routledge, New York 2017.

[85] Z. He, X. Wan, A. Schulz, H. Bludau, M. A. Dobrovolskaia, S. T. Stern, S. A. Montgomery, H. Yuan, Z. Li, D. Alakhova, Biomaterials 2016, 101, 296.

[86] M. Terzolo, A. Angeli, M. Fassnacht, F. Daffara, L. Tauchmanova, P. A. Conton, R. Rossetto, L. Buci, P. Sperone, E. Grossrubatscher, N. Engl. J. Med. 2007, 356, 2372.

[87] E. Silveira, I. P. Cavalcante, J. L. Kremer, P. O. R. de Mendonça, C. F. P. Lotfi, Cancer Cell Int. 2018, 18, 29.

[88] J. Friedrich, C. Seidel, R. Ebner, L. A. K. Schughart, Nat. Protoc. 2009, 4, 309.

[89] L. B. Weiswald, D. Bellet, V. Dangles Marie, Neoplasia 2015, 17, 1. 